\title{
LAS NOVELAS «GASEIFORMES» DE ENRIQUE LABRADOR RUIZ
}

\author{
POR \\ PERLA ROZENCVAIG \\ Barnard College, Columbia University
}

La narrativa de Enrique Labrador Ruiz se inicia (oficialmente) con la publicación de El laberinto de sí mismo ${ }^{1}$, en 1933. Tres años más tarde se publica Cresival, su segunda novela, con una nota aclaratoria que puede leerse como prólogo a posteriori de El laberinto. En esa nota Labrador explica cómo llegó a esa forma de novelar tan rechazada por la mayoría de sus contemporáneos por no corresponder a los modelos que dominaban el espacio narrativo de esa época. El lector ideal a quien supuestamente va dirigida la nota (y también sus novelas) se enfrenta a un texto-esqueleto que necesita que él lo rellene y articule para poder andar. Con la publicación de Anteo en 1940, Labrador completa su trilogía de novelas «gaseiformes». El término con el que ha unificado este corpus narrativo indica la consistencia del material lingüístico que será objeto de análisis en el presente estudio.

El hallazgo del mismo término en «El lapicerito de oro» ${ }^{2}$, de Azorín, nos permitió descubrir a ese «alguien" al que se refiere Labrador en la nota, ya que esa novela «en estado de gas, amorfa y con todo el atractivo de un sueño vago» ${ }^{3}$, como la definió Azorín en 1929, sedujo también al escritor cubano desde sus comienzos. Las afinidades inevitables que se producen entre los alteradores de cualquier orden exigen que al examinarse

\footnotetext{
${ }^{1}$ Enrique Labrador Ruiz, El laberinto de sí mismo (Montclair, N. J.: Senda Nueva de Ediciones, 1983). Todas las citas de la novela se refieren a esta segunda edición, la cual coincide con el cincuentenario de la novela.

2 Azorín, Superrealismo (Madrid: Biblioteca Nueva, 1929).

${ }^{3}$ Ibid., p. 11.
} 
estos textos se tengan en cuenta sus relaciones con la novela de vanguardia que apareció en Iberoamérica entre 1920 y 1930 . Novela que, en palabras de Ortega y Gasset, apela a un discurso «deshumanizante» e «intrascendente» al excluir de sus dominios la noción aristotélica del arte que reproduce los modelos de comunicación imperantes en el referente externo.

Labrador Ruiz trata a sus personajes con la misma soltura de Torres Bodet en Margarita de niebla (1927) o de Pedro Salinas en su colección de cuentos Víspera del gozo (1926). La niebla evocadora de la imprecisión y el gozo que reclama la utilización de la palabra sin trabas son precisamente las constantes de la obra labradoriana. Sus personajes, las situaciones en las que se ven involucrados y su continua manía de desinteresarse del asunto lo llevan a admitir su necesidad de «amarrar los cabos con cintas de agua» ${ }^{4}$. Pero curiosamente Labrador Ruiz, al mencionar a los escritores que han dejado algún rastro en su producción literaria, no menciona a ninguna de las figuras más representativas de la narrativa de vanguardia. Sólo recuerda a Eduardo Mallea sin aludir a su libro Cuentos para una inglesa desesperada (1926), el cual no debió haberle pasado inadvertido dada su amistad con él. Lo cierto es que Labrador, distanciado de preocupaciones telúricas y de la observación realista de un determinado fenómeno, produce su primera novela en un momento de convulsión política en Cuba (el gobierno de Gerardo Machado) que aparentemente no afecta al mundo que pueblan sus personajes.

$\mathrm{Ni}$ el yo narrador ni Laurell, su doble comportamiento, se refieren a la realidad político-social que les ha tocado vivir. Mucho menos los tres lápices pensantes que se disputan la palabra al comienzo de la historia. Estos, como el narrador de «El lapicerito de oro», texto antológico de la vanguardia española, viven inmersos en el proceso de la escritura. Y como para Labrador crear es en cierta medida ocultar, no sorprende el que uno de los lápices diga: «Las cosas que se explican dejan de ser. Son otra cosa después de explicadas. Yo mismo no comprendería eso si tuviera que explicármelo» ${ }^{5}$, por lo que el lector de El laberinto, para captar las señales del texto en su sentido más pleno, deberá desenterrar el discurso político que subyace debajo de las inquietudes estéticas de estos personajes, sobre todo si se trata de una lectura ideológica del texto. Ese escritor pobre, sin amigos, «sin prebendas políticas», dedicado a almacenar papeles que nadie quiere publicar, se le revela al lector, conocedor del contexto político y cultural al que apunta la novela, como un producto del aparato represivo

${ }^{4}$ Reinaldo Sánchez, Labrador Ruiz..., tal cual (Miami: Ediciones Hispamerican Books, 1984), p. 13.

${ }^{5}$ Labrador Ruiz, El laberinto, p. 19. 
que él (el escritor) borra del texto para atacarlo con lo único que posee: su escritura estratégica. Al no mencionar el personaje el sistema político que propicia la miseria y el desprecio para el que no transige con las fórmulas acuñadas, Labrador está señalando en silencio la necesidad de un cambio.

Es oportuno decir que Labrador insiste en que estas tres novelas constituyen una «triagonía», lo cual las inscribe dentro de la tradición de lucha que encierra la palabra en su origen griego. Labrador emprende la lucha en el nivel de la escritura, rebelándose en contra de las estructuras geométricas y racionales. En su lugar propone estructuras expansivas y enrevesadas cargadas de humor e irracionalidad que se desbordan de la página al contacto activo con el lector, entente cordiale decisivo en sus planes.

Como el humor tiende a confundir los géneros, las novelas «gaseiformes» ensanchan sus dimensiones, apropiándose del lirismo de la poesía, las reflexiones filosóficas características del ensayo y el diálogo dramático que poco o nada tienen que ver con la novela tradicional. Esta confluencia de fórmulas literarias correspondientes a otros géneros en la obra labradoriana estrecha su nexo con la narrativa de vanguardia. Labrador, con un sentido de libertad total, se deleita en llevar al extremo situaciones en las que los personajes se burlan hasta de su propia desgracia, como le ocurre a Mahomed Boranquín (Laurell) en El laberinto, quien se disfraza de faquir sin estar en carnaval para, con su máscara, como señala Bakhtin ${ }^{6}$, destacar lo grotesco y lo serio de su terrible situación.

-Sí, yo soy el fakir... El que liberta las almas con las imprevistas artes que atesora. Si todos los problemas se reducen a un traje perfecto, a una sonrisa de mujer, a la mirada de unos ojos azules... Pero si hay algo más... ${ }^{7}$

La frase queda suspendida. Ese «algo más» que se infiltra en el discurso de la simulación puede entenderse a la inversa: no hay nada más. El faquir improvisado no tiene trabajo. Es un artista cuyos actos de telepatía, espiritismo, hipnotismo o faquirismo apenas le permiten comer un huevo al día, lo cual no le impide compararse con los verdaderos faquires. «¿Cuántos fakires hay tan verdaderos como yo?» ${ }^{8}$, le comenta al narrador del texto. Su genuinidad proviene precisamente de la máscara, que delata y sostiene su condición de artista. Hasta la sonrisa que a veces visita a su rostro desprovisto de antifaz indica que no hay diferencia entre la máscara de su sonrisa-mueca y la máscara-artificio artístico con la que ejecuta su acto

\footnotetext{
${ }^{6}$ Mikhail Bakhtin, Rabelais and his World (Bloomington: Indiana, 1984).

${ }^{7}$ Labrador Ruiz, El laberinto, p. 28.

${ }^{8}$ Ibid., p. 30.
} 
de salvación. Ambas conviven en el espacio de la restricción y las vicisitudes metaforizado por la abstinencia del faquir.

Una estrategia interesante de Labrador es el otorgarle nombre propio (Laurell) al doble del narrador, además de nombrarlo por sus seudónimos artísticos. El narrador-protagonista, sin embargo, no aparece identificado. Se mantiene en la oscuridad del anonimato - señal de fracaso-- al que se ven condenados los metamorfoseos de Laurell y sus propias fabulaciones imaginativas. Representa un espíritu disidente en el que se funden distintas entidades corpóreas cuyo propósito común consiste en desestabilizar el orden que oblitera su existencia de creador acrático.

Las correspondencias entre la textura polifónica del personaje labradoriano y la escritura metamórfica desarrollada durante la vanguardia se tornan evidentes al escuchar la voz narrativa de Proserpina rescatada (1931), de Torres Bodet, novela paradigmática de la vanguardia mexicana:

Desde el primer momento, todos le habían adjudicado una doble personalidad, un talento de diosa cortado en dos partes por las diversidades del clima, como la Proserpina de la leyenda.

Más adelante, Proserpina convoca todas sus duplicaciones:

Impaciencia. Mi cuerpo me ha impuesto un límite demasiado opaco entre el mundo del sueño, en que soy Proserpina, sin epítetos, sin apellidos, sin dogmas, señora de mi infierno y esa tierra de vigilia en que me llamo Dolores Jiménez, doctora, teósofa, espiritista, partidaria de Krishna Murti, enemiga de la vacuna, devota de la Christian Science ${ }^{9}$.

Ambos escritores producen secuencias narrativas disasociadas mediante la interacción de personajes polivalentes cuya personalidad escindida quiebra la visión de mundo unívoco y coherente a la que se enfrentó la sensibilidad artística de los vanguardistas. Además, uno de los ambientes de la novela de Torres Bodet es la ciudad de Nueva York; Labrador Ruiz, por su parte, sitúa a sus personajes en una ciudad cuyo marco referencial es La Habana. La casa de vecindad (más conocida como «el solar»), los clubes nocturnos que huelen a vicio, las exposiciones de pintura supeditadas a la valoración crítica de la seudointelectualidad y los ambientes sórdidos de la urbe capitalina dan cuenta de una ciudad en decadencia física y mental. De Nueva York, sin embargo, Torres Bodet ofrece una visión más matizada, más a tono con el entusiasmo que sentían los vanguardistas por lo moderno.

\footnotetext{
9 Jaime Torres Bodet, Proserpina rescatada (Madrid: Espasa-Calpe, 1931), p. 23.
} 
Las dos novelas también son producto del recuerdo y del olvido, de la memoria transformada en estructuras lingüísticas difusas y descompuestas. La serie de recuerdos juveniles que el narrador de El laberinto y Proserpina recuperan respectivamente se materializan en traslados dispersivos y fluctuantes que sitúan su centro en la constante inestabilidad. Los núcleos narrativos se fragmentan, se desatan, revelando el esfuerzo de la memoria atolondrada por rescatar experiencias inconexas y atemporales. La misma estructuración de El laberinto - Un tiempo, Otro tiempo, Después - indica la supremacía del tiempo psíquico sobre el de la mecánica de la esfcra.

Aunque en El laberinto queda atrapada una serie variada de temas, es el de la creación el que recorre el espacio narrativo con más asiduidad. Escritura consciente y reflexiva que utiliza a su creador - el lápiz - como personaje crítico de su propia producción. El amor, la dualidad humana, la relación vida-muerte participan en el juego del texto, pero los mecanismos que podrían ordenar estos discursos mediante la presencia de un sujeto centro o de un lenguaje metafórico quedan supeditados a los caprichos de una memoria subversiva que trastorna las categorías y deja al descubierto el andamiaje que la sustenta.

Cresival, el protagonista de la novela del mismo título, también es víctima del olvido y la memoria que todo lo distorsiona. Marcado por el rechazo de la madre, que lo abandona en la consulta de una abortista, recibe un nombre trastrocado producto de la confusión entre Parsifal, el héroe germánico, y una medicina que se encontraba en el consultorio:

Entró al gabinete; sabía que el nombre estaba incompleto, incorrecto, torcido. ¿Cómo era, señor? Algo, algo faltaba en él. Ese ifal o ibal, o al, simplemente, repiqueteándole en el oído... Acaso... No; no aceptaba otra cosa.

-iPercival?

Vio sobre la mesilla el frasco de expectorante para los clientes.

Su nombre fue una luz. Gritó:

Cresival, señora, Cresival. Ya sabía yo que se me había olvidado ${ }^{10}$.

Aunque Teodora, la ayudante de la médico, se hace cargo del niño, su vida infantil queda reducida a mirar e imaginar. Inventa juegos extraños que lo aíslan de los demás y que le sirven de entrenamiento para la fabricación de sus historias de adulto. Estas aparecen en un libro que recibe la misma indiferencia e incomprensión con las que la crítica de la época juzgó a Cresival. Escritura que anticipa la realidad sin copiarla, que pro-

${ }^{10}$ Enrique Labrador Ruiz, Cresival (La Habana: Talleres Carasa, 1936), p. 28. 
yecta la sombra de un sujeto ausente y que anuda en secuencias díslocas la vida del autor y del personaje omnipresente.

Guillermo Villarronda ha señalado que la novela es un gran monólogo dialogante: «Un monólogo en el que el autor ha puesto mucho de su vida mental y afectiva..., personajes que no son otra cosa que desdoblamientos del personaje central»"

De la dislocación que la narración como totalidad asume se destacan los núcleos semánticos, que rinden un inventario de la demagogia política de la época. El discurso, sin alusiones temporales, pero con referencias espaciales que reiteran una visión frívòla y decadente del medio habanero, cuestiona desde dentro, con su propia estructura irreverente, no sólo las formas opresivas de poder, sino los productos culturales (en particular la novela de su época) sometidos a la retórica oficial. Cresival se propone como un viaje por el lenguaje neblinoso de lo desconocido y de lo extraño en el que el lector se encuentra frente a abstracciones en lugar de personajes que realizan una intensa función cognoscitiva y que, aunque en apariencia se desentienden de la problemática política, desencadenan un juego serio de alusiones destinadas a que se indague en las categorías de autoridad que el texto contiene.

Una certera treta labradoriana es plantear la dialéctica decencia-prostitución mediante la voz femenina. La bondad de Teresa en El laberinto, los buenos principios de Matilde en Cresival y el amor de Copelia en Anteo no impiden su descenso moral. Aceptan la explotación sexual y el sometimiento al hombre que les paga por un rato de placer como una condición inevitable de su propia naturaleza de mujer en una sociedad en la que las diferencias de sexo están marcadas por el desequilibrio y la injusticia social. Queda explicitado en la trilogía que la mujer, para sobrevivir, tiene que transigir, pactar desde su posición de ser inferior con los que disponen las reglas. Acosada, como la escritura que se instaura en el espacio de la desviación, se ve obligada a definirse y a aceptarse como un producto de consumo, deleite de los que pueden pagar sus favores. A diferencia del escritor marginado que se resiste a aceptar opciones degradantes, los personajes femeninos de estas historias son seres pasivos cuyo determinismo social pone en evidencia la tradición cultural en la que se han formado y paralizado.

Este tratamiento de los personajes femeninos parece justificado - aunque perturba e irrita tanta pasividad - si se tiene en cuenta que todavía hoy se escuchan planteamientos como el de Lacan: que «la mujer no tiene

1 Guillermo Villarronda, Tres novelas distintas y un solo autor verdadero (La Habana: La Verónica, 1941), p. 15. 
palabra». Que desde tiempos inmemoriales, como señala Virginia Woolf, un grupo de mujeres escribiera poesía en una isla griega no impidió que por miles de años estuvieran condenadas al silencio y sus nefastas consecuencias.

Sin embargo, en todo momento, las transfiguraciones que sufre la voz masculina en la trilogía se enfrentan con dignidad a sus censores y cuestionan su proceder. A simple vista, esto podría juzgarse como el resultado de una escritura masculina que, consciente o inconscientemente, se vuelve cómplice de su propio verdugo, pero una lectura atenta de estas novelas rechaza enérgicamente tales enjuiciamientos críticos. Labrador le niega a la voz femenina hasta la posibilidad de tomar conciencia de cuán denigrante es la función a la que ha quedado reducida para con el comportamiento que le ha impuesto hacer hincapié en la necesidad de una radicalización social generalizada. El, por su parte, desestabiliza el lenguaje de la novela subordinando sus núcleos semánticos a la incoherencia de una memoria profusa e imaginativa que funciona con la arbitrariedad característica del comportamiento humano.

Como Anteo, la última novela de la serie, aparece en un momento de supuesta reafirmación de lo autóctono mediante la recreación de un criollismo de peleas de gallo, cañaverales y moliendas de café, Labrador no consigue quien publique tal desafío lingüístico, y se ve forzado a utilizar sus propios fondos para publicar la novela en 1940. Sus convicciones sobre lo que él considera que debe ser un texto literario sustentan los comentarios del prólogo de la novela:

Mis personajes, criollos que no se apresuran a estarlo gritando en todas las esquinas, se reclutan donde quiera, pero sin empotrarse forzosamente en un pasaje de fondo agreste como anhelan los señores que están pidiendo una «novela cubana» a toda costa, tipo melcocha..., donde se conjuguen muchas veces «terrícola», «insular»..., junto a una melopea de voquibles guachinangos por tantas razones inaceptables... iNunca! Primero rompería mi pluma que hacer eso. ¡Aborrezco la farsa! ${ }^{12}$

El interés de Labrador por la mitología se materializa una vez más en el nombre del protagonista, Anteo. Hijo de Gea, la tierra, y Poseidón, el mar, se convierte en un gigante cuya fuerza, aunque extraordinaria, dependía de que se mantuviera en contacto con la tierra; de ahí que Heracles logre vencerlo cuando lo separa de ésta.

Fragmentos inconexos de la vida del personaje son rescatados por una memoria, interesada principalmente en registrar experiencias de la juven-

\footnotetext{
${ }^{12}$ Enrique Labrador Ruiz, Prólogo de Anteo (La Habana: Talleres Carasa, 1940), p. XXII.
} 
tud, época en que el protagonista era estudiante de arte, amaba y tenía ideales. Aunque la historia también tiene de marco referencial a La Habana, en los intersticios de esta memoria se entremezclan recuerdos de la guerra civil española con la situación de Europa en los albores de la Segunda Guerra Mundial. El viaje retrospectivo de Anteo comienza durante su entrenamiento en el cuerpo de bomberos. El protagonista se prepara para luchar contra el fuego destructor de la tierra, pero no puede librarse de su destino mitológico, ya que este entrenamiento es, precisamente, la prueba de su propio fracaso. Al reinvertir el mito, Labrador apega el personaje a la tierra, desprendiéndolo de sus más caros ideales, negándole toda posibilidad de realizarse como pintor o escultor. «Con esa proclividad de los personajes labradorianos — señala Rita Molinero-, Anteo, a pesar de sí mismo, está condenado por su tiempo y hasta por su nombre a un vivir terrenal en donde se le está vedado, a riesgo de perecer, cualquier elevación del espíritu» ${ }^{13}$.

Junto con la reelaboración del mito, Labrador emplea técnicas narrativas sumamente innovadoras para la década de los treinta. La técnica objetal, por ejemplo, característica del nouveau roman y tan utilizada por algunos de los novelistas del boom latinoamericano, le sirve a Labrador para delinear el personaje que queda nombrado sin aparecer en la descripción:

... camisa desgarrada, zurcida, restituida...; camisa de mangas con jirones, de botones con orín, de ojales sin morbidez; ectoplasmática levita cenicienta, de vuelta alta, bien alta, de solapas hasta arriba, hasta la nuez, hasta donde se puede soportar lo que es una solapa, ihasta donde no se puede jamás!; levita de estafermo, de espantanubes... ${ }^{14}$

También algunos de los mecanismos de artificialización que operan en las novelas «gaseiformes» (la superabundancia verbal y la fascinación con la metáfora hermética y retorcida) responden en cierta medida a la estética neobarroca. Aunque el predominio de lo barroco en la novela cubana ha sido extensamente estudiado en la obra de Lezama Lima, Alejo Carpentier y Severo Sarduy, las novelas labradorianas no han recibido aún la atención que merecen, no sólo por inscribirse dentro de una de las corrientes más fructíferas de la narrativa cubana, sino también por ser textos pioneros de la nueva novela hispanoamericana.

\footnotetext{
13 Rita Molinero, La narrativa de Enrique Labrador Ruiz (Madrid: Playor, 1977), p. 70.

14 Enrique Labrador Ruiz, Anteo, p. 43.
} 